\title{
Serosurvey of rabies virus, canine distemper virus, parvovirus, and influenza virus in military working dogs in Korea
}

\author{
Ha-Hyun KIM ${ }^{1)}$, Dong-Kun YANG ${ }^{1) *}$, Bo-Hyun SEO ${ }^{2)}$ and In-Soo $\mathrm{CHO}^{1)}$ \\ ${ }^{1)}$ Viral Disease Research Division, Animal and Plant Quarantine Agency, Gimcheon, Gyeongsangbuk-do, 39660, \\ Republic of Korea \\ ${ }^{2)}$ Military Working Dog Training Center, Chuncheon, Gangwon-do, 24408, Republic of Korea
}

\section{J. Vet. Med. Sci.}

80(9): 1424-1430, 2018

doi: 10.1292/jvms.18-0012

Received: 8 January 2018

Accepted: 22 July 2018

Published online in J-STAGE:

31 July 2018

\begin{abstract}
Rabies virus (RABV), canine distemper virus (CDV), canine parvovirus type-2 (CPV-2), and canine influenza A virus (CIV) are important contagious pathogens in canine populations. To assess post-vaccination immunity against RABV, CDV and CPV-2, and serological evidence of exposure to influenza A virus in military working dogs (MWDs) in Korea, we tested blood samples of $78 \mathrm{MWDs}$ by fluorescent antibody virus neutralization (FAVN) for RABV, and by commercially available enzyme-linked immunosorbent assay (ELISA) for CDV, CPV-2, and CIV. Korean MWDs had high antibody-positive rates against RABV (97.4\%, $\geq 0.5 \mathrm{IU} / \mathrm{m} /)$, CDV (94.8\%), and CPV (100\%). All dogs tested seronegative $(0 / 78 ; 0 \%)$ for influenza $A$ virus. Two 1-year-old dogs stationed in known rabies outbreak areas (Gangwon and Gyeonggi) exhibited VNA titers below the protective level ( 0.06 and $0.29 \mathrm{lU} / \mathrm{m} /$, respectively). The breed and sex of MWDs were not significantly associated with antibody titers for RABV, CDV, or CPV; however, age was significantly associated with CPV antibody titers, while region of residence was associated with CDV antibody titer. Taken together, the data presented here provide important insights necessary for post-vaccination management and control of infectious diseases in MWDs.
\end{abstract}

KEY WORDS: canine distemper virus, canine parvovirus, influenza A virus, military working dog, rabies virus

Rabies virus (RABV), canine distemper virus (CDV), canine parvovirus type-2 (CPV-2), and canine influenza A virus (CIV) are important infectious pathogens in canine populations, with significant implications for public health. RABV is a common pathogen capable of inducing fatal encephalitis in mammals, resulting in tens of thousands human deaths worldwide every year, with millions more at risk due to exposure to rabid animals [31]. Since its reoccurrence in raccoon dogs (Nyctereutes Procyonoides) in 1993, sylvatic rabies has been prevalent in the Gyeonggi and Gangwon provinces of Korea, located near the border of the demilitarized zone (DMZ). Since that time, raccoon dogs have remained the primary reservoir species, transmitting RABV to other animals including cattle, dogs, and cats [37]. Since 2000, the Korean veterinary authority has been vaccinating wild populations through the distribution of rabies bait vaccines, in combination with a mass vaccination program of dogs and cattle beginning in 1993 for both the Gyeonggi and Gangwon provinces. For mass vaccination program, the Korean authority has annually supported about 1.4 million doses of parenteral vaccine for dogs and cattle in rabies outbreak regions, and all dogs nationwide according to the Livestock Disease Prevention Plan. In order to prevent the reoccurrence of rabies and monitor the seropositive rates in the endemic regions (Gyeonggi and Gangwon provinces) following mandatory vaccination, serological monitoring has been implemented in dogs and cattle in two regions since 2002. The average seropositive rates of dogs and cattle in two regions were 65.3 and $46.5 \%$, respectively. These interventions appear to have been successful, with the incidence of non-human rabies cases decreasing gradually since its inception, and no new cases reported since 2014 [37].

Canine distemper (CD) is one of the most contagious and fatal diseases affecting all families of carnivores, including dogs and wild raccoons [10, 17, 29]. CDV (family Paramyxoviridae, genus Morbillivirus) infection is a multisystemic disease affecting the respiratory and gastrointestinal tracts, central nervous system, and various other organs and tissues, and can induce immunosuppression $[3,29]$. Although effective vaccines are commercially available, CD is still an important infectious disease in dogs and wild carnivores [24, 25, 32]. In many cases, progression of the disease may differ depending on factors such as the rearing environment, virus strain, age, and immune status of the individual $[3,17]$.

CPV-2 is one of the most important viral pathogen causing hemorrhagic enteritis in dogs [21]. Originally isolated in the 1970s

*Correspondence to: Yang, D.-K.: yangdk@korea.kr

O2018 The Japanese Society of Veterinary Science

This is an open-access article distributed under the terms of the Creative Commons Attribution Non-Commercial No Derivatives (by-nc-nd) License. (CC-BY-NC-ND 4.0: https://creativecommons.org/licenses/by-nc-nd/4.0/) 
from diarrhea samples of puppies, the virus has since been supplanted by new genetic and antigenic variants CPV-2a, CPV-2b, and CPV-2c in many countries worldwide $[9,21]$. Although many researchers have suggested that CPV vaccines developed using the original CPV-2 or CPV-2b strains can confer protective immunity against the current variants, cross-protection between original and variant CPVs remains a controversial topic $[9,21]$. However, despite these disagreements, widespread immunization using existing vaccines remains an essential tool for the prevention of these diseases [5, 26, 35].

CIVs are differentiated into two subtypes, the North American H3N8, which originated from horses, and the Asian H3N2, which originated from birds $[15,23,28,33]$. A retrospective serological study of the H3N2 virus has suggested the virus was first introduced in Korea as early as 2005 [16]. Other Korean cases include the H3N2 virus isolated from a dog with severe respiratory symptoms in 2007, and a reassortant H3N2 containing the M gene of the pandemic H1N1 in 2012 [22, 33]. Dogs are considered both a susceptible host, capable of infection by a wide variety of influenza viruses of equine, avian, and even human origin, as well as an intermediate host capable of spreading the virus due to their close contact with humans [12, 15, 23, 27]. Vaccination and monitoring for influenza virus infections in dogs is therefore needed to prevent the emergence of novel influenza viruses [23].

Due to their highly specialized lifestyle, military working dogs (MWDs) may represent both an important reservoir for viral infections of military service members, as well as potential victims of disseminated disease. To control disease outbreaks and protect MWD populations, regular vaccinations against RABV, CDV and CPV-2 were performed in accordance with standard guidelines except CIV [34].

To date, studies examining the seroprevalence of tick-borne infections and antibiotic resistance, as well as the genetic relatedness of Enterococcus sp. isolated from MWDs in Korea have been reported [2, 4]. However, there have been no serologic studies regarding the effectiveness of RABV, CDV, and CPV-2 vaccination, or CIV infection rates in MWDs in Korea.

The objective of this study was to evaluate seropositivity against RABV, CDV, CPV-2, and CIV in the Korean MWD population. We obtained blood samples from 78 MWDs and evaluated them for detection of protective antibody levels against RABV by fluorescent antibody virus neutralization (FAVN), antibodies formation against CDV and CPV, and serologic evidence of exposure to influenza A virus by a commercially available enzyme-linked immunosorbent assay (ELISA).

\section{MATERIALS AND METHODS}

\section{Serum samples}

Blood samples from 78 MWDs trained in the Korean military working dog training center were collected in June 2015 to investigate the antibody titer levels against RABV, CDV, CPV, and CIV. The initial puppy vaccinations and annual revaccinations have been administered in all MWDs against RABV, CDV and CPV-2 except CIV. Of the 78 dogs investigated in this study, 40 were from Gangwon province, 11 were from Gyeonggi province, 5 were from Incheon, 4 were from Chungbuk, 3 each from Gyeongbuk and Chungnam provinces, 2 each from Gyeongnam province, Seoul, and Sejong, and 1 each from Jeonnam, Jeonbuk province, Gwangju, Daegu, Daejeon, and Busan (Fig. 1). The years of birth of dogs were $2001(n=1), 2004(n=2), 2005(n=3)$, $2006(n=4), 2007(n=2), 2008(n=4), 2009(n=18), 2010(n=9), 2011(n=2), 2012(n=12), 2013(n=17)$, and 2014 (n=4). Breeds included Belgian Malinois (BM; $n=14)$, German Shepherd (GS; $n=53)$, Korean Jindo (KJ; $n=2)$, Labrador Retriever $(\mathrm{LR} ; n=8)$, and Shepinois (SN, mixed with German shepherd and Belgian Malinois; $n=1)$. Of these dogs, 49 (62.8\%) were male. Sera were separated from blood, aliquoted, and stored at $-70^{\circ} \mathrm{C}$ until used.

\section{FAVN test for $R A B V$}

Viral neutralizing antibody (VNA) titers against RABV were determined by FAVN test using standards set forth by the World Organization for Animal Health (OIE). Briefly, three-fold dilutions of each serum sample were serially conducted in four wells. WHO reference serum was diluted to $0.5 \mathrm{IU} / \mathrm{m} l$ for use as a positive control. Stock CVS-11 virus was prepared as $100 \mathrm{TCID}_{50} / 50 \mu l$, and $50 \mu l$ of diluted virus was added to each well. Samples were then incubated at $37^{\circ} \mathrm{C}$ for $1 \mathrm{hr}$, after which $50 \mu \mathrm{l}$ of BHK-21 cells suspension $(4 \times$ $10^{5}$ cells $/ \mathrm{m} l$ ) was added to each well. Microplates containing a mixture of sera, virus, and cells were then incubated at $37^{\circ} \mathrm{C}$ in a humid incubator with $5 \% \mathrm{CO}_{2}$ for $48 \mathrm{hr}$. Afterwards, the medium was removed, and the cells fixed in $80 \%$ cold acetone for $30 \mathrm{~min}$. Cells were then incubated with RABV-specific monoclonal antibody and stained with FITCconjugated goat anti-mouse IgG (KPL, Gaithersburg, MD, U.S.A.). Fluorescence was observed under a fluorescence microscope and the results of each well were recorded.

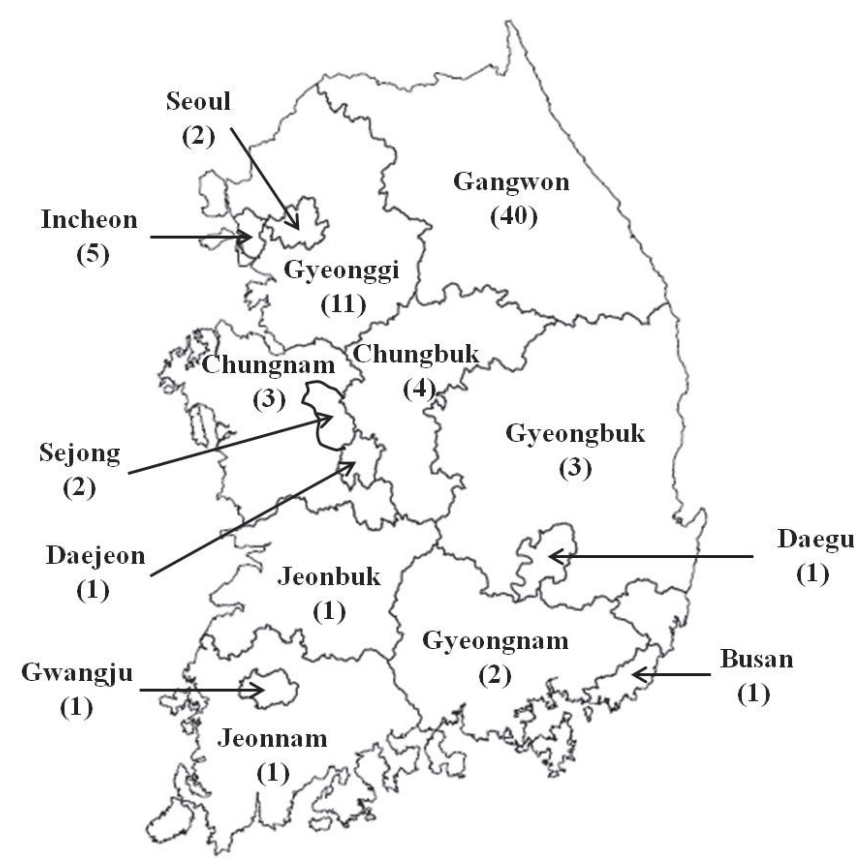

Fig. 1. Map of the region of residence and the number of 78 military working dogs investigated in this study. 
Table 1. The number of dogs showing each viral neutralizing antibody titer against rabies virus in 78 Korean military working dogs by age

\begin{tabular}{|c|c|c|c|c|c|c|c|c|c|c|c|c|c|}
\hline \multirow{2}{*}{$\begin{array}{c}\text { Age } \\
\text { (year-old) }\end{array}$} & \multicolumn{12}{|c|}{ VNA titer $(\mathrm{IU} / \mathrm{m} l)^{\text {a) }}$} & \multirow{2}{*}{$\begin{array}{c}\text { No. seropositive/tota } \\
(\%)\end{array}$} \\
\hline & 0.06 & 0.29 & 0.87 & 1.51 & 2.62 & 4.56 & 7.92 & 13.77 & 23.93 & 41.59 & 72.27 & 125.59 & \\
\hline 14 & & & & & & & & & & 1 & & & $1 / 1$ \\
\hline 11 & & & & & & & & 1 & 1 & & & & $2 / 2$ \\
\hline 10 & & & & & & & 2 & 1 & & & & & $3 / 3$ \\
\hline 9 & & & & & & & 1 & 1 & & 2 & & & $4 / 4$ \\
\hline 8 & & & & & & & & 2 & & & & & $2 / 2$ \\
\hline 7 & & & & & & & & 1 & 1 & 2 & & & $4 / 4$ \\
\hline 6 & & & & & & & 5 & 3 & 6 & 3 & & 1 & $18 / 18$ \\
\hline 5 & & & & 1 & & 1 & 1 & 1 & 2 & 2 & & 1 & $9 / 9$ \\
\hline 4 & & & & & & & 1 & 1 & & & & & $2 / 2$ \\
\hline 3 & & & & & & 3 & 3 & 4 & 1 & & & 1 & $12 / 12$ \\
\hline 2 & & & 1 & & 1 & 3 & 1 & 7 & 1 & 2 & 1 & & $17 / 17$ \\
\hline $1^{\text {b) }}$ & 1 & 1 & & & 1 & 1 & & & & & & & $2 / 4$ \\
\hline Total & 1 & 1 & 1 & 1 & 2 & 8 & 14 & 22 & 12 & 12 & 1 & 3 & $76 / 78$ (97.4) \\
\hline
\end{tabular}

a) Viral neutralizing antibody (VNA) titers against rabies virus (RABV) were determined by fluorescent antibody virus neutralization (FAVN) test. The protective VNA titers more than $0.5 \mathrm{IU} / \mathrm{m} l$ were indicated as seropositive against RABV. b) The VNA titers $(0.29$ and $0.06 \mathrm{IU} / \mathrm{m} l)$ of 2 dogs were lower than protective level $(0.5 \mathrm{IU} / \mathrm{m} l)$ among 4 military dogs born in 2014 .

\section{ELISA test for CDV, CPV, and influenza A virus}

All sera of MWDs were tested for detection of antibodies against CDV, CPV, and influenza A virus by ELISA. The ELISA tests were conducted using commercially available ELISA kits including the Ingezim Moquillo IgG kit (Ingenasa, Madrid, Spain), Ingezim Parvo Canino kit (Ingenasa), and influenza A virus kit (Bionote, Hwaseong, Korea) according to the manufacturers' instructions. The Moquillo IgG kit detects IgG antibodies against CDV using a microplate coated with a CDV recombinant protein. The CPV-like particles-coated microplates of the Parvo Canino kit are used for detection of antibodies to CPV in dog serum. In these tests, $100 \mu l$ of sample and control sera were added to the test plates, and incubated for $10 \mathrm{~min}$ at room temperature. After washing, the microplate was incubated with $100 \mu \mathrm{l}$ of conjugate for $10 \mathrm{~min}$ and read at $450 \mathrm{~nm}$. For the CDV and CPV assays, presence of color was indicative of antibodies against virus in the sera. The antibody titers [Y (titer) $=54\left(\mathrm{e}^{4 \mathrm{X}}\right), \mathrm{X}=\mathrm{S} / \mathrm{P}(\mathrm{sample} \mathrm{OD} /$ positive control $\mathrm{OD}$ ) ratio] to $\mathrm{CPV}$ were calculated according to the manufacturers' instructions. In contrast, the influenza A ELISA works by competitive hybridization, with the absence of color signifying the presence of antibodies against influenza A virus.

\section{Statistical analysis}

Statistical significance was assessed by one-way analysis of variance (ANOVA) for age, region, and breed, and a two-tailed $t$-test used for comparisons between two groups such as sexes and specific regions (Gyeonggi and Gangwon provinces). All comparisons were performed using GraphPad Prism software (Version 7.0), with $P$ values $<0.05$ considered statistically significant.

\section{RESULTS}

\section{VNA titers against RABV in MWDs}

To investigate seropositivity rates of MWDs against RABV in Korea, blood samples from 78 MWDs born between 2001 and 2014 were obtained from a Korean MWD training center in 2015. Of these 78 dogs, only two dogs, both born in 2014, exhibited VNA titers $(0.29$ and $0.06 \mathrm{IU} / \mathrm{m} l)$ lower than protective level $(0.5 \mathrm{IU} / \mathrm{m} l)$; all other dogs $(76 / 78 ; 97.4 \%)$ showed RABV antibody titers $\geq 0.87 \mathrm{IU} / \mathrm{m} l$, well above the protective threshold (Table 1). No significant differences in mean VNA titers were observed between age groups $(1,2,3,5,6,7$ and 9-year-old groups, minimum four individuals per group; $P=0.5705)$. MWDs originated from 15 regions of Korea (Gangwon, Gyeonggi, Gyeongnam, Gyeongbuk, Jeonnam, Jeonbuk, Chungnam, Chungbuk, Seoul, Sejong, Incheon, Gwangju, Daegu, Daejeon, and Busan) (Fig. 1). Of these areas, the two dogs found to have VNA titers below the protective threshold were working in Gangwon and Gyeonggi provinces $(0.06 \mathrm{IU} / \mathrm{m} l$ and $0.29 \mathrm{IU} / \mathrm{m} l$, respectively; Table 2). Further analysis revealed no significant difference in mean values of VNA titers according to region (Gangwon, Gyeonggi, Chungbuk and Incheon, $\mathrm{n} \geq 4, P=0.0813$ ); however, comparisons of mean VNA titers between endemic rabies provinces (Gyeonggi and Gangwon) revealed that the mean titer of dogs working in Gyeonggi was significantly lower than that of Gangwon (Gangwon, $n=40$; Gyeonggi, $n=11 ; P=0.0296$ ) (data not shown).

Of the five breeds included in this study (BM, GS, KJ, LR, and SN), RABV VNA titers below the protective level ( $0.5 \mathrm{IU} / \mathrm{m} l)$ were found in two breeds, GS and LR. Male dogs were more common in our study $(49 / 78 ; 62.8 \%)$, though sex was not associated with sub-protective VNA titers, with one male and female in this group $(0.06 \mathrm{IU} / \mathrm{m} l$ and $0.29 \mathrm{IU} / \mathrm{m} l$, respectively). Comparisons of mean VNA titers according to breed (BM, GS, and LR) and sex revealed no significant differences between groups (breed, $P=0.5984$; sex, $P=0.1718$ ) (data not shown). 
Table 2. The number of dogs showing each viral neutralizing antibody titer against rabies virus in 78 Korean military working dogs by region of residence

\begin{tabular}{|c|c|c|c|c|c|c|c|c|c|c|c|c|c|}
\hline \multirow{2}{*}{ Region } & \multicolumn{12}{|c|}{ VNA titer $(\mathrm{IU} / \mathrm{m} l)^{\mathrm{a})}$} & \multirow{2}{*}{$\begin{array}{c}\text { No. seropositive/total } \\
(\%)\end{array}$} \\
\hline & 0.06 & 0.29 & 0.87 & 1.51 & 2.62 & 4.5 & 7.92 & 13.77 & 23.93 & 41.59 & 72.27 & 125.59 & \\
\hline Gangwon & $1^{\text {b) }}$ & & & & & 1 & 9 & 11 & 8 & 8 & 1 & 1 & $39 / 40$ \\
\hline Gyeonggi & & $1^{b)}$ & & 1 & 1 & 3 & 1 & 3 & 1 & & & & $10 / 11$ \\
\hline Gyeongnam & & & & & & & & 2 & & & & & $2 / 2$ \\
\hline Gyeongbuk & & & & & & & & & & 3 & & & $3 / 3$ \\
\hline Jeonnam & & & & & & & & & 1 & & & & $1 / 1$ \\
\hline Jeonbuk & & & & & & & & 1 & & & & & $1 / 1$ \\
\hline Chungnam & & & & & & & 1 & 1 & 1 & & & & $3 / 3$ \\
\hline Chungbuk & & & 1 & & & 2 & & & 1 & & & & $4 / 4$ \\
\hline Seoul & & & & & & & 1 & & & & & 1 & $2 / 2$ \\
\hline Sejong & & & & & & & & 2 & & & & & $2 / 2$ \\
\hline Incheon & & & & & & 2 & 1 & 1 & & 1 & & & $5 / 5$ \\
\hline Gwangju & & & & & & & & & & & & 1 & $1 / 1$ \\
\hline Daegu & & & & & 1 & & & & & & & & $1 / 1$ \\
\hline Daejeon & & & & & & & 1 & & & & & & $1 / 1$ \\
\hline Busan & & & & & & & & 1 & & & & & $1 / 1$ \\
\hline Total & 1 & 1 & 1 & 1 & 2 & 8 & 14 & 22 & 12 & 12 & 1 & 3 & 76/78 (97.4) \\
\hline
\end{tabular}

a) Viral neutralizing antibody (VNA) titers against rabies virus were determined by fluorescent antibody virus neutralization (FAVN) test. The protective VNA titers more than $0.5 \mathrm{IU} / \mathrm{m} l$ were indicated as seropositive against RABV. b) The VNA titers of 2 dogs working in Gangwon (0.06 IU/m $l$ ) and Gyeonggi $(0.29 \mathrm{IU} / \mathrm{m} l)$ was lower than protective level $(0.5 \mathrm{IU} / \mathrm{m} l)$.

A

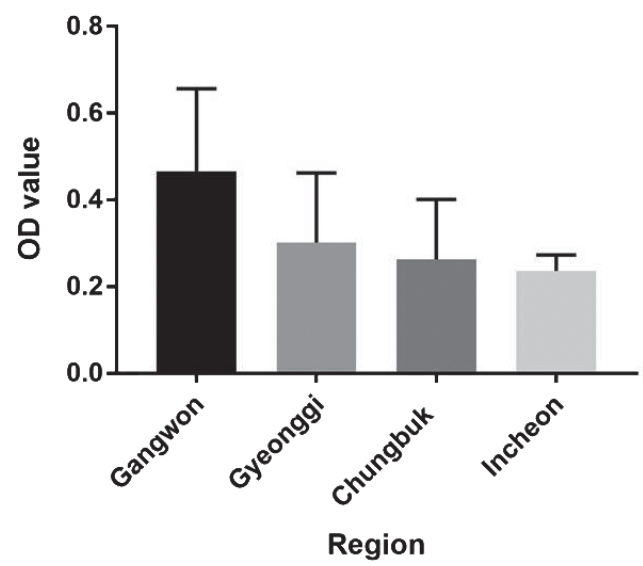

B

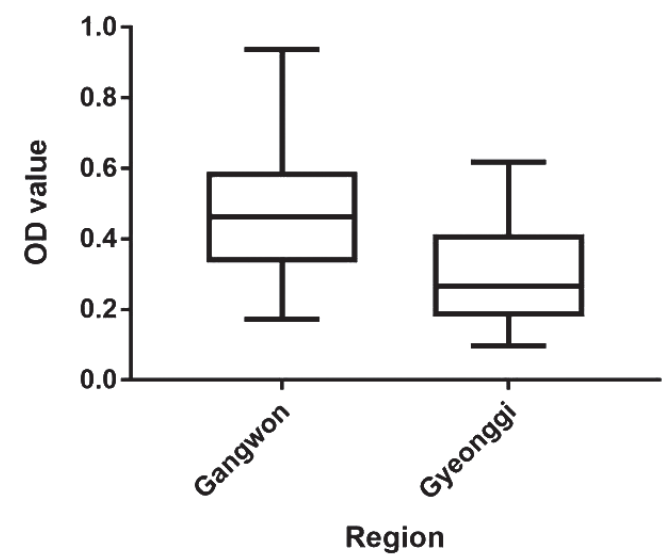

Fig. 2. Mean ELISA OD values for canine distemper virus (CDV) analyzed according to region of residence. Comparisons of CDV antibody levels across four regions (Gangwon, Gyeonggi, Chungbuk and Incheon, $n \geq 4$ ) (A). Comparison of mean CDV antibody titers between Gyeonggi $(n=11)$ and Gangwon $(n=40)$ provinces (B). Significant differences in mean antibody levels were evident across the four (A, $P=0.0028)$ and two (B, $P=0.0117$ ) regions tested. Antibody levels are presented as mean values \pm standard errors.

\section{Detection of antibodies for CDV in MWDs}

Serological testing for the detection of antibodies against CDV was conducted using a commercially available ELISA kit. In total, 74/78 (94.8\%) dogs were seropositive for antibodies against CDV. Despite the annual vaccination, four dogs, a 5-year-old female GS and a 1-year-old female LR residing in Gyeonggi, along with two 6-year-old male GSs residing in Gyeongnam and Chungbuk, tested negative for CDV antibodies. ELISA results revealed no significant differences in CDV antibody levels between age groups (1-3, 5-7 and 9-year-old groups, $\mathrm{n} \geq 4 ; P=0.292$ ). Comparisons of CDV antibody levels across four regions (Gangwon, Gyeonggi, Chungbuk and Incheon, $\mathrm{n} \geq 4$ ) showed significant differences in mean antibody titers according to region $(P=0.0028$; Fig. 2A). Further comparisons of mean CDV antibody titers between Gyeonggi $(n=11)$ and Gangwon $(n=40)$ provinces revealed that the mean titer of dogs working in Gangwon was significantly higher than that of Gyeonggi ( $P=0.0117$; Fig. 2B). In contrast, no significant differences were evident between breeds (BM, GS, and LR) or sexes ( $P=0.2076$ and $P=0.1654$, respectively) (data not shown). 


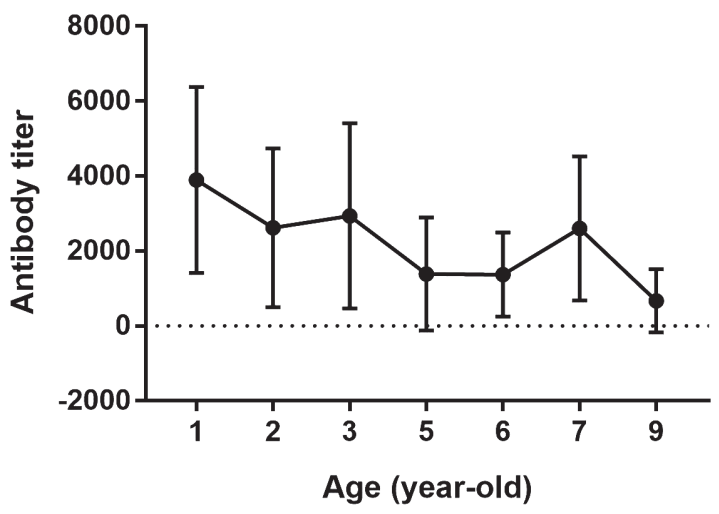

Fig. 3. Mean viral antibody titers for canine parvovirus (CPV) in Korean military working dogs were analyzed according to age. Analysis by one-way ANOVA to test for linear trends in mean CPV antibody levels over time revealed a significant decrease across 1 to 9-year-old dogs $(P=0.015)$. The antibody titers $\left[\mathrm{Y}(\mathrm{titer})=54\left(\mathrm{e}^{4 \mathrm{X}}\right), \mathrm{X}=\mathrm{S} / \mathrm{P}(\right.$ sample OD/ positive control OD) ratio] to CPV were calculated. Antibody titers are presented as mean values \pm standard errors.

\section{Detection of antibodies against CPV and influenza A virus}

Next, ELISAs were performed using commercially available kits for detection of antibodies against CPV and influenza A virus. All MWDs were seropositive against CPV (78/78, 100\%). However, despite seropositivity in all animals, we did observe significant differences in CPV antibody titers between age groups ( $1-3,5-7$ and 9-year-old groups, $\mathrm{n} \geq 4 ; P=0.04)$, with titers decreasing with age in 1 to 9 -year-old dogs $(P=0.015$ by one-way ANOVA for linear trends; Fig. 3$)$. Differences in CPV titers according to region, breed, and sex were not significantly different ( $P=0.7917, P=0.4518$, and $P=0.4636$, respectively) (data not shown). In contrast to $\mathrm{CPV}$, all dogs were seronegative for influenza A virus $(0 / 78,0 \%)$.

\section{DISCUSSION}

RABV, CDV, and CPV-2 are highly fatal and contagious viral agents affecting dogs. The rabies vaccine is effective at preventing dog-mediated rabies, the source of $>95 \%$ of all human cases, while vaccination against CDV and CPV-2 significantly decreases the spread of these diseases in canine populations [5, 14, 19, 35]. CIV is either equine or avian in origin, and is considered an important epizootic agent due to the probability of emergence of novel viral strains as a result of reassortment between human and canine viruses [23].

Serological assays are useful tools for assessing post-vaccination immunity against RABV, CDV, and CPV-2, and can provide evidence of exposure to influenza A virus $[1,8,11,16,26]$. Proactive surveillance for antibody formation may therefore represent an important part of routine health screenings, ensuring adequate defense against viral infections for both MWDs and military service members. In this study, we obtained blood samples from 78 MWDs and screened for viral antibodies against RABV, CDV, $\mathrm{CPV}$, and influenza A virus to assess post-vaccination immunity and viral exposure in these animals.

Protective VNA titers against RABV were detected in nearly all WMDs (76/78; 97.4\%), well above the 70\% immunization coverage considered necessary to contain rabies outbreaks in dog populations [7]. Based on these data, it is believed that most MWDs possess antibody levels capable of defending against a subsequent RABV exposure. Age, region, breed, and sex of MWDs were not significantly associated with the level of protective antibody responses against RABV in this study; however, two young dogs, both $\sim 1$-year-old, exhibited VNA titers below the protective threshold in spite of vaccination. While mean VNA titers were not significantly different between age groups in this study, protective antibody titers $\geq 0.5 \mathrm{IU} / \mathrm{m} l$ were consistently observed in older dogs by previous study [26]. Such an observation is not surprising, given that the number of vaccinations is strongly related to antibody titer $[6,18,26]$. Together, these data suggest that greater focus needs to be placed on ensuring VNA formation reaches protective levels following vaccination in young dogs.

Although no significant difference was revealed in mean values of VNA titers according to region, the mean titer of MWDs in Gyeonggi was significantly lower than that of Gangwon. Animal rabies consistently occurred in Gangwon by 2012, unlike Gyeonggi. But, the most recent cases were detected in Gyeonggi in 2012 and 2013. Therefore, we need to pay attention to vaccination of livestock including MWDs in Gyeonggi province. In addition, the two dogs exhibiting VNA titers below the protective threshold were both stationed in known rabies outbreak areas, Gangwon and Gyeonggi provinces. As RABV exposure is typically higher in known outbreak areas due to increased contact with wild animals, a thorough vaccination program in combination with serological validation is necessary for each MWD in Gangwon and Gyeonggi provinces.

CDV and CPV-2 vaccines are regularly administered alongside the rabies vaccine in MWDs, in accordance with standard vaccination guidelines [34]. In this study, we observed high seropositivity rates against both CDV (94.8\%) and CPV (100\%). These antibody-positive rates are considered high enough to protect against viral infections via herd immunity [35], and may negate the need for annual revaccination due to the high seroprevalence against these pathogens $[20,36]$. In the present study, neither breed 
nor sex were significantly associated with antibody titers to CDV or CPV, in agreement with previous reports [20, 36]. However, we did see a significant association between CDV antibody titer and region of residence, as well as CPV antibody titers and age. While previous report has suggested that antibody retention for CDV was positively associated with age by vaccination or environmental exposure [35]. However, others have suggested that age was not significantly associated with the CDV antibody titers in vaccinated animals $[20,26,30,36]$, consistent with the results presented here. In contrast, comparisons of CDV antibody levels showed significant differences according to region (Gangwon, Gyeonggi, Chungbuk and Incheon). Furthermore, the mean titer of dogs working in Gangwon was significantly higher than that of Gyeonggi. As seropositive rates against CDV in wild raccoon dogs were 97.2 and $63.6 \%$ in Gangwon and Gyeonggi provinces, respectively [38], this seems to be due not only to the vaccine effect but also to environmental exposure.

In the case of CPV, Twark and Dodds (2000) showed that age was not significantly related to antibody responses against CPV, regardless of breed or sex [36]. However, other studies have reported that antibody titers to CPV were higher in younger animals, consistent with the findings presented here [20, 26, 35]. It has been suggested that high antibody formation against CPV in younger dogs was attributable to more active cell division and stronger immune responses in young individuals [13, 35].

The small number of MWDs included in our study represents a significant divergence from the more general dog populations used in other studies, making direct comparisons more difficult. Regardless, our data show that persistent monitoring of risk factors including age and region of residence, and serological testing following vaccination are strongly recommended in MWDs group. In our previous study, seropositive rates against CDV (89.4\%) and CPV (24.5\%) are high in wild raccoon dogs in both provinces, the likely exposure to these viruses is significant [38]. Therefore, routine vaccination may represent an important defense against viral transmission from MWDs to the surrounding wildlife, providing an added level of protection against infection [5].

In Korea, H3N2 CIV was introduced as early as 2005, with positive identification in dog achieved in 2007. Subsequent reassortment of the H3N2 virus to incorporate the M gene of the pandemic H1N1 strain first appeared in 2012 [16, 22,33$]$. Although two commercially available H3N8 CIV vaccines and one conditionally approved H3N2 CIV vaccine have recently been developed [23], the CIV vaccine is generally not administered to MWDs to protect against CIV infection. This lack of vaccine-based immunity means that it is reasonable to think that MWDs exposed to CIV may have seroconverted. However, such a phenomenon was not appeared in the data, with all $78 \mathrm{dogs}(0 \%)$ testing negative for influenza A virus antibodies. Such a result seems to indicate that there have been no active influenza A virus infections affecting the Korean MWD population prior to June 2015 .

In conclusion, Korean MWDs were able to achieve high antibody-positive rates against RABV, CDV, and CPV via routine vaccination, while remaining seronegative for influenza A virus. Two 1-year-old dogs stationed in known rabies outbreak areas showed VNA titers below protective levels. Neither breed nor sex were significantly associated with antibody titers to RABV, CDV, or CPV. In contrast, age was significantly associated with CPV antibody titers, while region of residence was associated with CDV antibody titer. Taken together, the results presented here may help to inform future infection control efforts and post-vaccination management strategies for MWDs.

ACKNOWLEDGMENT. This study was supported by a grant (N-1549085-2017-36-01) from Animal and Plant Quarantine Agency, Ministry of Agriculture, Food, and Rural Affairs (MAFRA), Republic of Korea.

\section{REFERENCES}

1. Aubert, M. F. 1992. Practical significance of rabies antibodies in cats and dogs. Rev. - Off. Int. Epizoot. 11: 735-760. [Medline] [CrossRef]

2. Bang, K., An, J. U., Kim, W., Dong, H. J., Kim, J. and Cho, S. 2017. Antibiotic resistance patterns and genetic relatedness of Enterococcus faecalis and Enterococcus faecium isolated from military working dogs in Korea. J. Vet. Sci. 18: 229-236. [Medline] [CrossRef]

3. Beineke, A., Puff, C., Seehusen, F. and Baumgärtner, W. 2009. Pathogenesis and immunopathology of systemic and nervous canine distemper. Vet. Immunol. Immunopathol. 127: 1-18. [Medline] [CrossRef]

4. Bell, D. R., Berghaus, R. D., Patel, S., Beavers, S., Fernandez, I. and Sanchez, S. 2012. Seroprevalence of tick-borne infections in military working dogs in the Republic of Korea. Vector Borne Zoonotic Dis. 12: 1023-1030. [Medline] [CrossRef]

5. Cleaveland, S., Kaare, M., Knobel, D. and Laurenson, M. K. 2006. Canine vaccination—providing broader benefits for disease control. Vet. Microbiol. 117: 43-50. [Medline] [CrossRef]

6. Cliquet, F., Verdier, Y., Sagné, L., Aubert, M., Schereffer, J. L., Selve, M., Wasniewski, M. and Servat, A. 2003. Neutralising antibody titration in 25,000 sera of dogs and cats vaccinated against rabies in France, in the framework of the new regulations that offer an alternative to quarantine. Rev. - Off. Int. Epizoot. 22: 857-866. [Medline] [CrossRef]

7. Coleman, P. G. and Dye, C. 1996. Immunization coverage required to prevent outbreaks of dog rabies. Vaccine 14: 185-186. [Medline] [CrossRef]

8. Coyne, M. J., Burr, J. H., Yule, T. D., Harding, M. J., Tresnan, D. B. and McGavin, D. 2001. Duration of immunity in dogs after vaccination or naturally acquired infection. Vet. Rec. 149: 509-515. [Medline] [CrossRef]

9. Decaro, N. and Buonavoglia, C. 2012. Canine parvovirus - a review of epidemiological and diagnostic aspects, with emphasis on type 2c. Vet. Microbiol. 155: 1-12. [Medline] [CrossRef]

10. Deem, S. L., Spelman, L. H., Yates, R. A. and Montali, R. J. 2000. Canine distemper in terrestrial carnivores: a review. J. Zoo Wildl. Med. 31: 441-451. [Medline] [CrossRef]

11. Greene, C. E. and Appel, M. J. 1998. Canine distemper. pp. 9-22. In: Infectious Diseases of the Dog and Cat (Greene, C. E. ed.), W. B. Saunders, Philadelphia.

12. Harder, T. C. and Vahlenkamp, T. W. 2010. Influenza virus infections in dogs and cats. Vet. Immunol. Immunopathol. 134: 54-60. [Medline] [CrossRef]

13. Hueffer, K. and Parrish, C. R. 2003. Parvovirus host range, cell tropism and evolution. Curr. Opin. Microbiol. 6: 392-398. [Medline] [CrossRef] 
14. Lamm, C. G. and Rezabek, G. B. 2008. Parvovirus infection in domestic companion animals. Vet. Clin. North Am. Small Anim. Pract. 38: 837-850, viii-ix. [Medline] [CrossRef]

15. Lee, E., Kim, E. J., Kim, B. H., Song, J. Y., Cho, I. S. and Shin, Y. K. 2016. Molecular analyses of H3N2 canine influenza viruses isolated from Korea during 2013-2014. Virus Genes 52: 204-217. [Medline] [CrossRef]

16. Lee, Y. N., Lee, D. H., Lee, H. J., Park, J. K., Yuk, S. S., Sung, H. J., Park, H. M., Lee, J. B., Park, S. Y., Choi, I. S. and Song, C. S. 2012. Evidence of H3N2 canine influenza virus infection before 2007. Vet. Rec. 171: 477. [Medline] [CrossRef]

17. Liu, P. C., Chen, C. A., Chen, C. M., Yen, C. H., Lee, M. H., Chuang, C. K., Tu, C. F. and Su, B. L. 2016. Application of xenogeneic anti-canine distemper virus antibodies in treatment of canine distemper puppies. J. Small Anim. Pract. 57: 626-630. [Medline] [CrossRef]

18. Mansfield, K. L., Burr, P. D., Snodgrass, D. R., Sayers, R. and Fooks, A. R. 2004. Factors affecting the serological response of dogs and cats to rabies vaccination. Vet. Rec. 154: 423-426. [Medline] [CrossRef]

19. Martella, V., Elia, G. and Buonavoglia, C. 2008. Canine distemper virus. Vet. Clin. North Am. Small Anim. Pract. 38: 787-797, vii-viii. [Medline] [CrossRef]

20. McCaw, D. L., Thompson, M., Tate, D., Bonderer, A. and Chen, Y. J. 1998. Serum distemper virus and parvovirus antibody titers among dogs brought to a veterinary hospital for revaccination. $J$. Am. Vet. Med. Assoc. 213: 72-75. [Medline]

21. Miranda, C. and Thompson, G. 2016. Canine parvovirus: the worldwide occurrence of antigenic variants. J. Gen. Virol. 97: 2043-2057. [Medline] [CrossRef]

22. Moon, H., Hong, M., Kim, J. K., Seon, B., Na, W., Park, S. J., An, D. J., Jeoung, H. Y., Kim, D. J., Kim, J. M., Kim, S. H., Webby, R. J., Webster, R. G., Kang, B. K. and Song, D. 2015. H3N2 canine influenza virus with the matrix gene from the pandemic A/H1N1 virus: infection dynamics in dogs and ferrets. Epidemiol. Infect. 143: 772-780. [Medline] [CrossRef]

23. Na, W., Yeom, M., Yuk, H., Moon, H., Kang, B. and Song, D. 2016. Influenza virus vaccine for neglected hosts: horses and dogs. Clin. Exp. Vaccine Res. 5: 117-124. [Medline] [CrossRef]

24. Nagao, Y., Nishio, Y., Shiomoda, H., Tamaru, S., Shimojima, M., Goto, M., Une, Y., Sato, A., Ikebe, Y. and Maeda, K. 2012. An outbreak of canine distemper virus in tigers (Panthera tigris): possible transmission from wild animals to zoo animals. J. Vet. Med. Sci. 74: 699-705. [Medline] [CrossRef]

25. Origgi, F. C., Plattet, P., Sattler, U., Robert, N., Casaubon, J., Mavrot, F., Pewsner, M., Wu, N., Giovannini, S., Oevermann, A., Stoffel, M. H., Gaschen, V., Segner, H. and Ryser-Degiorgis, M. P. 2012. Emergence of canine distemper virus strains with modified molecular signature and enhanced neuronal tropism leading to high mortality in wild carnivores. Vet. Pathol. 49: 913-929. [Medline] [CrossRef]

26. Ottiger, H. P., Neimeier-Förster, M., Stärk, K. D., Duchow, K. and Bruckner, L. 2006. Serological responses of adult dogs to revaccination against distemper, parvovirus and rabies. Vet. Rec. 159: 7-12. [Medline] [CrossRef]

27. Ozawa, M. and Kawaoka, Y. 2013. Cross talk between animal and human influenza viruses. Annu. Rev. Anim. Biosci. 1: 21-42. [Medline] [CrossRef]

28. Payungporn, S., Crawford, P. C., Kouo, T. S., Chen, L. M., Pompey, J., Castleman, W. L., Dubovi, E. J., Katz, J. M. and Donis, R. O. 2008. Influenza A virus (H3N8) in dogs with respiratory disease, Florida. Emerg. Infect. Dis. 14: 902-908. [Medline] [CrossRef]

29. Pope, J. P., Miller, D. L., Riley, M. C., Anis, E. and Wilkes, R. P. 2016. Characterization of a novel canine distemper virus causing disease in wildlife. J. Vet. Diagn. Invest. 28: 506-513. [Medline] [CrossRef]

30. Rikula, U., Nuotio, L. and Sihvonen, L. 2000. Canine distemper virus neutralising antibodies in vaccinated dogs. Vet. Rec. 147: 598-603. [Medline] [CrossRef]

31. Rupprecht, C., Kuzmin, I. and Meslin, F. 2017. Lyssaviruses and rabies: current conundrums, concerns, contradictions and controversies. F1000 Res. 6: 184. [Medline] [CrossRef]

32. Schumaker, B. A., Miller, M. M., Grosdidier, P., Cavender, J. L., Montgomery, D. L., Cornish, T. E., Farr, R. M., Driscoll, M., Maness, L. J., Gray, T., Petersen, D., Brown, W. L., Logan, J. and O’Toole, D. 2012. Canine distemper outbreak in pet store puppies linked to a high-volume dog breeder. J. Vet. Diagn. Invest. 24: 1094-1098. [Medline] [CrossRef]

33. Song, D., Kang, B., Lee, C., Jung, K., Ha, G., Kang, D., Park, S., Park, B. and Oh, J. 2008. Transmission of avian influenza virus (H3N2) to dogs. Emerg. Infect. Dis. 14: 741-746. [Medline] [CrossRef]

34. Song, W. J., Kim, H. T., Yoo, H. S. and Youn, H. Y. 2014. Guidelines for vaccination of dogs and cats in Korea. Clin. Exp. Vaccine Res. 3: $244-247$. [Medline] [CrossRef]

35. Taguchi, M., Namikawa, K., Maruo, T., Orito, K., Lynch, J. and Sahara, H. 2011. Antibody titers for canine parvovirus type-2, canine distemper virus, and canine adenovirus type-1 in adult household dogs. Can. Vet. J. 52: 983-986. [Medline]

36. Twark, L. and Dodds, W. J. 2000. Clinical use of serum parvovirus and distemper virus antibody titers for determining revaccination strategies in healthy dogs. J. Am. Vet. Med. Assoc. 217: 1021-1024. [Medline] [CrossRef]

37. Yang, D. K., Kim, H. H., Lee, K. K., Yoo, J. Y., Seomun, H. and Cho, I. S. 2017. Mass vaccination has led to the elimination of rabies since 2014 in South Korea. Clin. Exp. Vaccine Res. 6: 111-119. [Medline] [CrossRef]

38. Yang, D. K., Kim, H. H., Nah, J. J., Choi, S. S., Kim, J. T., Jeong, W. H. and Song, J. Y. 2013. Serologic survey of rabies virus, canine distemper virus and parvovirus in wild raccoon dogs (Nyctereutes procyonoides koreensis) in Korea. J. Bacteriol. Virol. 43: 204-209. [CrossRef] 